\title{
The Need for Transdisciplinarity in Psychiatry and Addiction Medicine
}

\author{
Ovidiu Alexinschi MD, PhD* \\ Senior psychiatrist, INSTITUTE OF PSYCHIATRY SOCOLA, IASI, Romania \\ *Corresponding author: Ovidiu Alexinschi, Senior psychiatrist, INSTITUTE OF PSYCHIATRY SOCOLA, IASI, Romania
}

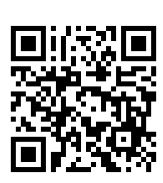

\begin{tabular}{|c|c|}
\hline ARTICLE INFO & ABSTRACT \\
\hline Received: 些 February 12, 2020 & \multirow{3}{*}{$\begin{array}{l}\text { Transdisciplinarity means not only multi- or interdisciplinarity - the addition or } \\
\text { pooling of several specialties - but an added value of the whole team with the raising } \\
\text { of scientific and collaborative standards, with the stated purpose of offering the best } \\
\text { standards of super-specialized medical services in the view of substantially increasing } \\
\text { the quality and life of patients. There is already a strong body of scientific evidence that } \\
\text { in chronic diseases, the integrated and transdisciplinary collaborative model of patient } \\
\text { care leads to improved patient health. The aggregated experience leads to the conclusion } \\
\text { that Transdisciplinarity fits with the bio-psycho-social model in Psychiatry and addiction } \\
\text { medicine. }\end{array}$} \\
\hline Published: 㓞 February 19, 2020 & \\
\hline $\begin{array}{l}\text { itation: Ovidiu Alexinschi MD, PhD. The } \\
\text { Jeed for Transdisciplinarity in Psychiatry } \\
\text { and Addiction Medicine. Biomed J Sci \& } \\
\text { ech Res 25(4)-2020. BJSTR. MS.ID.004246. }\end{array}$ & \\
\hline
\end{tabular}

Keyword: Transdisciplinarity in Psychiatry; Addiction Medicine

\section{Short Communication}

Transdisciplinary medicine represents the next level in the modern holistic approach of patients, implying not only the collaboration of the medical disciplines but also the raising of the standards of healthcare assistance beyond the fragmented vision of each specialty. There is already scientific evidence that in chronic diseases, the integrated and transdisciplinary collaborative model of patient care leads to improved patient health [1]. It is true that mastery of psychiatry also implies broad perspectives for sociology, psychology, philosophy, art, spirituality and in general for everything that can help the healing of the soul, but if we want a solid position as a medical discipline we must definitely anchor ourselves in medical logic and to stop the sterile pendulum between interesting hypotheses only as an intellectual exercise but not scientifically validated. The word Transdisciplinarity appears to have been introduced by eminent Swiss psychologist Jean Piaget in 1970 at a seminar on interdisciplinarity in universities held at the University of Nice and jointly sponsored by the Organization of Economic Cooperation and Development and the French Ministry of Education [2].

The conclusion of Piaget's [3] essay on various kinds of interaction between the disciplines mentions Transdisciplinarity offhand, as a kind of an aside, as a "higher stage succeeding interdisciplinary relationships. . . which would not only cover interactions or reciprocities between specialized research projects, but would place these relationships within a total system without any firm boundaries between disciplines". The Romanian researcher Nicolescu [4,5] magisterially describes Transdisciplinarity as complementing the disciplinary approaches. His concept of Transdisciplinarity focuses on complexity as a fundamental feature of reality, on the premise of different levels and dimensions of reality, and on what he calls the logic of the included middle, in defiance of the Aristotelian axiom of the excluded middle, suggesting that Nicolescu, in the spirit of quantum mechanics, wants scientists to "rethink" the traditional absolute separation of the subject and the object [2].

Nicolescu's Transdisciplinarity has implications to the integration of the humanities, including spiritual subjects such as religion, and philosophies of knowledge and education with physical science subjects such as those extant in laboratories and space observatories. Nicolescu concerns himself with the meaning of going beyond disciplines and asserts that "Transdisciplinarity identifies with a new knowledge about what is between, across, and beyond disciplines (the meaning of trans)" [6]. Nevertheless, 
he encourages scholars to go beyond the dichotomous, either/ or mentality that, in his view, produced many of the problems that now plague humanity. What sets Transdisciplinarity apart from other approaches and what assures its role in twenty firstcentury education is its acceptance of, and its focus on, the inherent complexity of reality that is seen when one examines a problem or phenomenon from multiple angles and dimensions. The multidimensional field of neuroscience had to open itself to Transdisciplinarity to include Information Technology, Quantum Physics, Psychology, Psychopathology or Neurology, surpassing the concept that psychological activity is only the product of neuronal activity and that goes deep through the different levels of reality in the nucleus.

For better understanding we have to point out the distiction between multidisciplinary, interdisciplinary and transdisciplinary. Especially due to the fact that the more general term "multiple disciplinary" is suggested for when the nature of involvement of multiple disciplines is unknown or unspecified. Multidisciplinarity draws on knowledge from different disciplines but stays within their boundaries. Interdisciplinarity analyzes, synthesizes and harmonizes links between disciplines into a coordinated and coherent whole. Transdisciplinarity integrates the natural, social and health sciences in a humanities context, and transcends their traditional boundaries. The objectives of multiple disciplinary approaches are to resolve real world or complex problems, to provide differentperspectives on problems, to create comprehensive research questions, to develop concensus clinical definitions and guidelines, and to provide comprehensive health services. Multiple disciplinary teamwork has both benefits and drawbacks. The three terms refer to the involvement of multiple disciplines to varying degrees on the same continuum [7]. With their own specific meanings, these terms should not be used interchangeably.

The more general term "multiple disciplinary" is suggested for when the nature of involvement of multiple disciplines is unknown or unspecified. While multiple disciplinary teamwork is appropriate for complex problems, it is not always necessary in every single project. To provide comprehensive services such as health care and health education multiple disciplinary teamwork is required in health and social care, such as primary health care [8]. There is little documented evidence in the literature about the effectiveness of multiple disciplinary teamwork. The limited available evidence indicates conflicting results. In theory, multiple disciplinary approaches are necessary to resolve real world, complex problems. Multiple disciplinary teamwork can provide different perspectives on a problem by generating comprehensive prospective hypotheses before a study and providing comprehensive post-hoc theories to explain study results. Multiple disciplinary teams have been found with success in situations such as consensus clinical definitions for complex diseases, and comprehensive health care services and health education.
Transdisciplinarity therefore means not only multi- or interdisciplinarity - the addition or pooling of several specialties but an added value of the whole team with the raising of scientific and collaborative standards, with the stated purpose of offering the best standards of super-specialized medical services in the view of substantially increasing the quality and life of patients. For illustration, in the case of diabetes, a chronic disease, widespread, intensely debilitating, at present, the patient comes in contact with the family doctor, nutritionist, neurologist (for diabetic PNP), nephrologist (nephropathy), internist, cardiologist, psychiatrist (organic depressive affective disorder) etc. being forced to navigate through the health system without being coordinated or, as the case may be, guided by its educational, motivational or financial capabilities. A transdisciplinary team coordinated by a case manager, comprising the listed specialties, with specific training and knowing not only the strictly professional part but possessing indepth knowledge and additional common skills including effective communication would bring net health benefits, shortening the time, reducing the direct and indirect costs, with improving the functionality of the patients.

The principles behind the collaborative, integrated and transdisciplinary care are:

Patient-Centered Care: Family physicians collaborate effectively with specialists using common care plans based on the patient's therapeutic goals and goals. The ability to provide medical care focused on both physical and mental health reduces duplication of patient evaluations, increases patient engagement in the medical record, and leads to improved health outcomes for patients. As well as an experience of providing improved medical services.

Population-Centered Care: Transdisciplinary teams share a defined group of patients tracked through a registry ensuring that no patient escapes medical supervision. Medical teams track patients and identify patients who do not improve their health as measured by biological parameters, and patient-centered care specialists provide consultations for this group not just individually but also as a group to guide the medical team.

Evaluation of the Treatment in Relation to the Therapeutic Targets: Each therapeutic plan clearly identifies the clinical targets accepted by the patient and related to the therapeutic targets as defined in the clinical guidelines, the clinical results are routinely measured using valid instruments. The treatments are changed if the health of the patients does not improve. Medical teams are making efforts so that the patient's therapeutic goals are closer to the therapeutic goals defined in the clinical guidelines (Stepped Care) [9].

Care Based on Scientific Evidence: Patients receive treatments that have scientific evidence based on scientifically valid research, 
highlighting their effectiveness in reaching the therapeutic goals of the medical condition.

Responsible Care: The medical team is responsible for the quality of the medical act taking into account, the scientific evidence and the existing resources,

The benefits of transdisciplinary psychiatry and addiction medicine could be [10-12]:

1) Improvement of depressive symptoms, functional activities and quality of life (QoL) in elderly patients with depression, compared to usual care.

2) Improvements in mental health related to QoL, depressive symptoms, substance use disorders, treatment rates and general functioning.

3) Reduction of depression and anxiety in patients with COPD or heart failure (which were maintained at the 12-month follow-up), as well as improvement of health-related quality of life in patients with COPD compared to regular care.

4) Short and long-term improvements in anxiety and depression symptoms compared to regular care in patients with corneal disease.

In synthesis, I believe that transdisciplinary approach in psychiatry and addiction medicine represents the logical and qualitative huge switch in the nowadays holistic approach of patients, comprising more than cooperation of the medical disciplines and therefore upgrading of the standards of healthcare assistance far beyond the unique vision of each specialty.

\section{References}

1. Evidence Base. AIMS Center Advancing Integrated Mental Health Solutions.

\section{ISSN: 2574-1241}

DOI: $10.26717 / B J S T R .2020 .25 .004246$

Ovidiu Alexinschi MD, PhD. Biomed J Sci \& Tech Res

(c) (P) This work is licensed under Creative

Submission Link: https://biomedres.us/submit-manuscript.php
2. Nicolescu B (2010) Methodology of transdisciplinarity: Levels of reality, logic of the included middle and complexity. Transdisciplinary Journal of Engineering \& Science 1(1): 19-38.

3. Piaget J (1972) The epistemology of interdisciplinary relationships. In Centre for Educational Research and Innovation (CERI), Interdisciplinarity: Problems of teaching and research in universities. Paris, France: Organisation for Economic Co-operation and Development, pp. 127-139.

4. Nicolescu B (2002) Manifesto of transdisciplinarity (K. C. Voss, Trans.). Albany, NY: State University of New York Press, USA.

5. Nicolescu B (2012) Transdisciplinarity: The hidden third, between the subject and the object. Human and Social Studies 1(2): 13-28.

6. Sue LT Mc Gregor (2015) The Nicolescuian and Zurich Approaches to Transdisciplinarity. Peer Reviewed Articles. Integral Leadership Review.

7. Dyer JA (2003) Multidisciplinary, interdisciplinary, and transdisciplinary education models and nursing education. Nurs Educ Perspect 24(4): 186-188.

8. Poulton BC, West MA (1993) Effective multidisciplinary teamwork in primary health care. J Advanced Nursing 18(6): 918-925.

9. http://aims.uw.edu/resource -library / measurement-based-treatmenttarget

10. Huffman AC, Mastromauero CA, Beach SR, Celano CM, Du Bois CM, et al. (2014) Collaborative care for depression and anxiety disorders in patients with recent cardiac events. The management of sadness and anxiety in cardiology (MOSIAC) randomized clinical trial. JAMA Intern Med 174(6): 927-935.

11. Cully JA, Stanley MA, Petersen NJ, Hundt NE, Kauth MR, et al. (2017) Delivery of brief cognitive behavioral therapy for medically ill patients in primary care: a pragmatic randomized clinical trial. J Gen Intern Med 32(9): 1014-1024.

12. Archer J, Bower P, Gilbody S, Lovell K, Richards D, et al. (2012) Collaborative care for depression anxiety problems. Cochrane Database Syst Rev 10: CD006525.

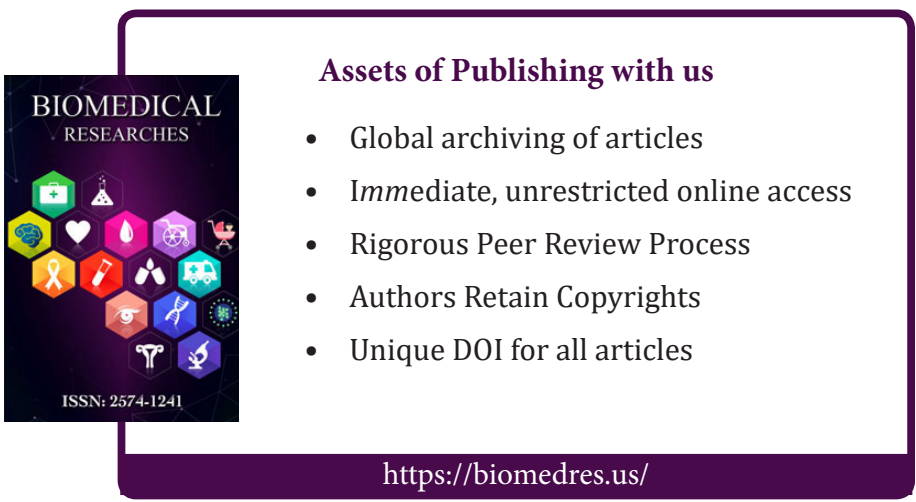

